\title{
Determinants to Performance of Multipurpose Agricultural Cooperatives (MPACs): A Case of Gondar Zuria District, North Gondar, Ethiopia
}

\author{
Assefa Adane ${ }^{1, ~ *, ~ D e g s e w ~ M e l a k ~}{ }^{2}$, Wuletaw Mekuria ${ }^{2}$ \\ ${ }^{1}$ Department of Animal Production and Extension, University of Gondar, Gondar, Ethiopia \\ ${ }^{2}$ Department of Rural Development and Agricultural Extension, University of Gondar, Gondar, Ethiopia \\ Email address: \\ asselal448@gmail.com (A. Adane), assefa.adane@uog.edu.et (A. Adane) \\ ${ }^{*}$ Corresponding author
}

\section{To cite this article:}

Assefa Adane, Degsew Melak, Wuletaw Mekuria. Determinants to Performance of Multipurpose Agricultural Cooperatives (MPACs): A Case of Gondar Zuria District, North Gondar, Ethiopia. International Journal of Economic Behavior and Organization.

Vol. 8, No. 2, 2020, pp. 23-30. doi: 10.11648/j.ijebo.20200802.11

Received: September 17, 2019; Accepted: October 26, 2019; Published: April 28, 2020

\begin{abstract}
Cooperatives enable people to improve their social and economic conditions by pooling their resource and efforts together in ways that are more productive than working individually. The aim of this study was to identify determinants to performance of MPACs. Multistage sampling was employed to select study area and sample households. Study area selected purposively because of its accessibility and relatively large numbers of functional cooperatives. Primary data were collected from 122 members of sample cooperatives those were selected using simple random sampling proportional to size of members in the cooperative through semi-structured interview schedule and key informant interview and focus discussion. Moreover, secondary data were obtained from audit reports of sample cooperatives. The collected data entered to SPSS version 20. Descriptive analysis such as mean, percentage and frequency were analyzed along with probit model. However, their moderate involvement in service provision of agricultural input distribution cooperatives output marketing service in the study area was found as it was not outstanding that majority of the cooperatives did not carry out purchasing of farmers output. The model result revealed that from thirteen explanatory variables included in the model for analysis numbers of shareholding in cooperative, membership to union and working relationship in cooperative were found to be significantly and positively related to members' satisfaction to overall performance of MPACs. On the other hand, family size of household, cooperative age and degree of corruption in cooperative were found to be significantly influence degree of member's satisfaction to their cooperative overall performance negatively. Therefore, cooperative management and staff members should strive to render valuable services to its members.
\end{abstract}

Keywords: Cooperative, Determinants, Multipurpose and Performance

\section{Introduction}

People have been helping each other and working together through their traditional form of cooperative organizations in Ethiopia. They have been organizing themselves in Iqub ${ }^{1}$ and $\mathrm{Idir}^{2}$ so as to help each other [1]. However; modern form of cooperatives started during the reign of Emperor Haile Selassie I to achieve common goals of the society [2]. The

1It refers to Ethiopian traditional saving association 2It refers to Ethiopian traditional Insurance association cooperatives are organized based on members' interest, free market participation and free of government intervention in the governance of the cooperatives [3]. Through cooperatives, individual households and communities can create opportunities for themselves, find a productive work that not only facilitate their wellbeing and stability but also give them the power to improve their lives and remain active in civil rights and political aspects [4]. Performances of MPACs are not satisfactory and low level of member's involvement is being informed in many cooperatives in Ethiopia [5]. Limited managerial capacity, low member's participation in decision 
making and controlling their organizations activities, shortage of finance, inadequate market information and basic infrastructure are the challenges facing Ethiopian cooperatives [6]. There were little or no study conducted in the study area to assess determinants to performance of multipurpose agricultural cooperatives (MPACs). Therefore, this study was conducted to fill this knowledge gap to assess the performance of MPACs in Gondar Zuria District. The main objective of this study is to assess determinants to performance of MPACs.

\section{Research Methodology}

\subsection{Description of Study Area}

The study was conducted in Gondar Zuria District in North Gondar Zone, Amhara National Regional State of Ethiopia. It has an estimated total population of 264,920 (out of this 130,796 were males and 134,124 were females). About $10.24 \%$ of its population is urban dweller, which is less than the zone average of $14.1 \%$. The rural area constitutes 40,551 households, with an estimated area of 1,286.76 square kilometers [7]. There are about 410 MPACs in North Gondar zone with total members of 215,830 (189621 male and 36, 209 female) and total working capital of 50,083,466.35 ETB. According to the Gondar Zuria District cooperative promotion office report there are 10 types of other agriculture related cooperatives, five saving and credit cooperatives, two consumer cooperatives, two solar energy primary cooperatives, two road construction and 22 MPACs. Those twenty two MPACs in the district comprises of total members of 19147 (16469 are males) and (2678 are females) with total capital of $3,808,918.32$ ETB.

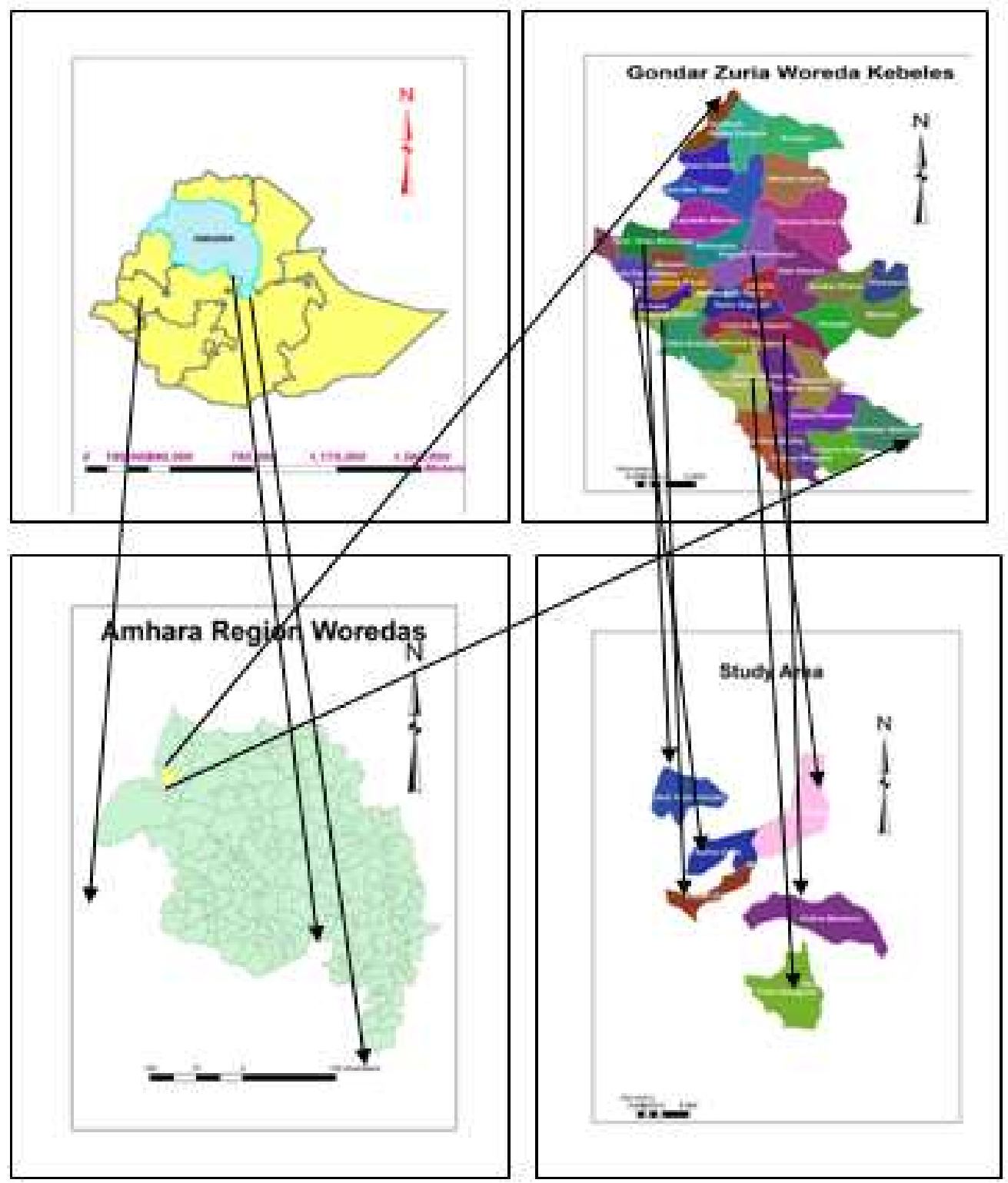

Figure 1. Map of study area. 


\subsection{Data Collection and Analysis}

Household survey using semi-structured interview schedule was conducted to collect primary data from 122 members of six sample cooperatives. Moreover, focus group discussion and key informant interview were conducted with the cooperatives' members, officials, and other key informants. Besides, secondary data were collected from annual report of cooperative, reputable journals, and CSA documents. Multistage sampling procedure was employed to select the study area, MPACs and members of sample cooperatives. In the first stage Gondar Zuria District purposively selected from North Gondar Zone because of its accessibility and relative number of cooperatives. In the second stage, out of twenty two MPACs found in this District six MPACs were selected purposively on the basis of their auditing status through consultation with District cooperative promotion office experts. Third, members of sample cooperatives were selected using systematic random sampling in probability proportional to the membership size.

Table 1. Sample size distribution by sample MPACs.

\begin{tabular}{lll}
\hline Name of MPACs & $\begin{array}{l}\text { Total numbers of } \\
\text { cooperatives' member }\end{array}$ & $\begin{array}{l}\text { Selected numbers of } \\
\text { members }\end{array}$ \\
\hline LayiyeDuge & 970 & 12 \\
JejaBahariginib & 810 & 10 \\
Dangure & 1844 & 23 \\
TachTeda & 2588 & 32 \\
DegoelaChinchay & 1226 & 16 \\
ChihraMaterno & 2219 & 29 \\
Total & 9657 & $\mathbf{1 2 2}$ \\
\hline
\end{tabular}

Source: Gndar Zuria District cooperative promotion office, 2017.

The data collected from household survey organized, coded and entered in to SPSS version 20 and descriptive statistical analysis such as mean, percentages and frequency. Probit model was employed to analyze determinants to performance of cooperatives considering members' satisfaction as indicator to overall performance of their cooperatives.

\section{Results and Discussions}

\subsection{Demographic Characteristics of Sample Households}

Demographic characteristics of the cooperative members are expected to influence performance of their cooperatives. As a result, basic information about the sample respondents was collected. As indicated in table 2 larger proportion of the sample respondents i.e. $61.5 \%$ representing males. Majority of the respondent's age group lies above 35 years. This could imply that most of the adult and elderly those could have better economical and social status who are expected to actively participate in cooperative because of they develop more experience that enable them to manage things easily. When we see respondents proportion in terms of marital status, 82, 9.8, 2.5 and 5.7 percent of the respondents were married, single, divorced and widowed respectively (Table 2).
Thus most of the members of the cooperatives are male headed households this might have influence on cooperative performance.

Table 2. Basic demographic characteristics of respondents $(N=122)$.

\begin{tabular}{llll}
\hline Variables & Categories & Frequency & Percent \\
\hline \multirow{2}{*}{ Sex } & Male & 75 & 61.5 \\
& Female & 47 & 38.5 \\
Age & $18-35$ years & 48 & 39.3 \\
& $36-49$ & 38 & 31.2 \\
& $50-65$ & 27 & 22.1 \\
& 66 and above & 9 & 7.4 \\
Marital status & Single & 12 & 9.8 \\
& Married & 100 & 82 \\
Educational level & Widowed & 7 & 5.7 \\
& Divorced & 3 & 2.5 \\
& Illiterate & 53 & 43.4 \\
& Able to read \& write & 26 & 21.3 \\
& Primary & 31 & 25.4 \\
& Secondary & 7 & 5.7 \\
& Diploma \& above & 5 & 4.1 \\
\hline
\end{tabular}

Source: survey data, 2017.

With regard to educational levelthe survey result showed that $(43.4 \%)$ of the respondents were illiterate had not received any type of education. It also revealed that $21.3 \%$ of the respondents able to read and write. As shown in the abovetable majority of the respondents were illiterate. Thus, they might not involve actively in cooperative activities and might have little information about the performance of their cooperative.

Majority of the respondents have 4-7 (5.15 mean) family members (figure 1). This could be an opportunity to MPACs to serve their members that most of the cooperative members require large amount of basic consumer goods as well as agricultural inputs. And they could have more number of share to access services in proportion to their family members thereby they might invest more capital through buying more numbers shares and actively involve in cooperative.

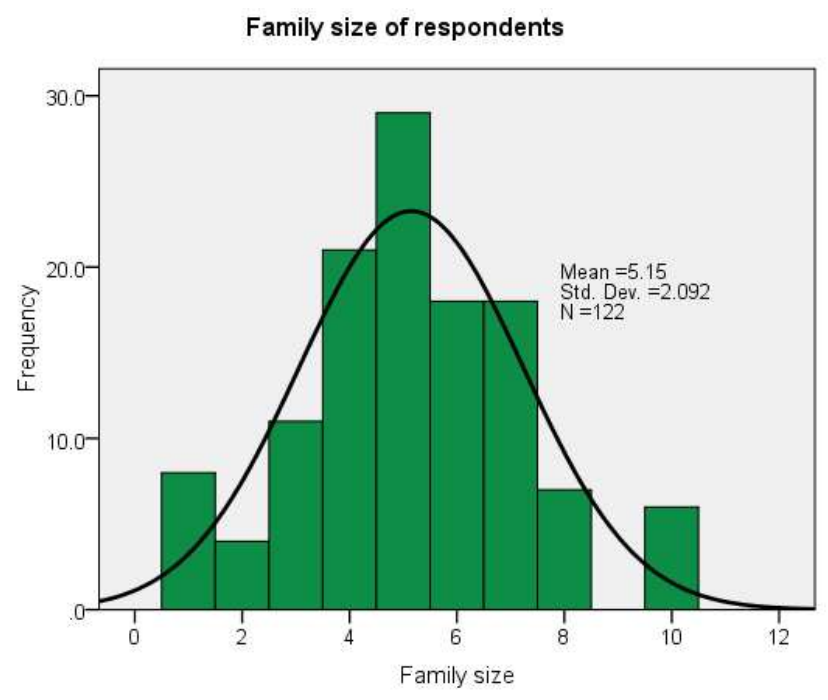

Figure 2. Family size distribution of households. 


\subsection{Membership and Participation of Members in Cooperative}

\subsubsection{Motivations to Become a Member}

Respondents of sample cooperatives were asked about the motivation or means for joining their cooperatives. The most pertinent motivating factors for majority of the members to join their cooperative was own interest and free choice of respondents $(61.5 \%)$. This reveals that majority of the members were become member to cooperative through their own initiatives and they can take part in cooperative affairs voluntarily. Farmers become members to cooperative through awareness creation by cooperative promoters accounts for (18\%) and the remaining $20.5 \%$ of respondents were become members by friends and/or neighbors influence (Table 3). This indicates that $38.5 \%$ of respondents were become member through other means rather than their own motivation. Hence, to participate actively in cooperative activities members need to be motivated through various means of incentives.

Table 3. Membership and member's participation in cooperatives.

\begin{tabular}{|c|c|c|c|}
\hline Variables & Categories & Frequency & Percent \\
\hline \multirow{4}{*}{$\begin{array}{l}\text { Motives to } \\
\text { become } \\
\text { member }\end{array}$} & Own accord/interest & 75 & 61.5 \\
\hline & Through promotion & 22 & 18 \\
\hline & Neighbor and/or friends influence & 25 & 20.5 \\
\hline & To get agricultural input supply & 34 & 30.3 \\
\hline \multirow{4}{*}{$\begin{array}{l}\text { purposes } \\
\text { to become } \\
\text { member }\end{array}$} & To get output market access & 37 & 27.9 \\
\hline & To get credit access & 1 & 0.8 \\
\hline & To get training & 21 & 17.2 \\
\hline & To get dividend income & 29 & 23.8 \\
\hline \multirow{5}{*}{$\begin{array}{l}\text { Sense of } \\
\text { ownership }\end{array}$} & High & 31 & 25.4 \\
\hline & Medium/ on average & 29 & 23.8 \\
\hline & Low & 27 & 22.1 \\
\hline & No sense of ownership & 35 & 28.7 \\
\hline & Total & 122 & 100 \\
\hline
\end{tabular}

Source: survey data, 2017.

\subsubsection{Purposes to Become a Member}

People joined cooperatives to get benefits that cannot be afforded through individual effort. As presented in table 3 out of total respondents $30.3 \%$ of the respondents have joined to cooperative to get market access. Farmers who become member to cooperative for the purpose of accessing agricultural inputs supply and training accounts for $27.9 \%$ and $17.2 \%$ (Table 3 ) of the respondents respectively. However, the remaining $23.8 \%$ and $0.8 \%$ of the respondents joined to get dividend income and credit access respectively. Here, to keep members actively involved, cooperative managements should render things they joined for. If members do not get what they expect from cooperative, their contribution in cooperative activities will be low this could have effect on the performance of cooperatives.

\subsubsection{Sense of Ownership of Members to Cooperatives}

Cooperatives deserve members to involve more and seek to increase sense of ownership. As indicated in table 3 about $25.4 \%$ of the respondent members expressed as they have high sense of ownership for the cooperatives whereas $28.7 \%$ of respondents opined as they do not have sense of ownership.
In this regard one can sense that either the cooperative are not in a position of providing the desirable services to members or the members are not cognizant of the cooperatives role and involved in cooperative activities simply considered as registered member.

\subsubsection{Duration of Membership and Numbers of Shareholding}

In this study majority of the members comprising $92.6 \%$ replied as they had 1-2 numbers of shares from their cooperatives. Only a few members have purchased more than two numbers of shares (Table 4). This depicts that most of cooperative members have purchased minimum amount of shares from their cooperatives which is required of them bylaw up to $10 \%$ shareholding for individuals. The possible explanation in this regard as raised by key informants cooperative managements did not motivate members to make additional investment through purchasing more numbers of shares in the cooperatives by offering desirable services for members. For instance, they did not conduct well organized marketing activities, did not bring other goods and farm equipments rather than basic consumer goods and did not distribute dividend. As a result, majority of the members' invested in most of the cooperatives range from 11 to $20 \mathrm{ETB}$ per share.

Table 4. Membership and member's participation in cooperatives.

\begin{tabular}{llll}
\hline Variables & Categories & Frequency & Percent \\
\hline \multirow{2}{*}{ Numbers of } & 1-2 shares & 113 & 92.6 \\
shareholding & 3-4 shares & 8 & 6.6 \\
& More than 4 & 1 & 0.8 \\
Duration of & 1-5 years & 50 & 41 \\
membership & 6-10 years & 55 & 45.1 \\
& More than 10 years & 17 & 13.9 \\
& Total & 122 & 100 \\
\hline
\end{tabular}

Source: survey data, 2017.

As indicated in the above table out of the total respondents $41 \%$ of them have been members for 1 to 5 years in cooperatives. Out of the total respondents $45.1 \%$ have been members of cooperatives for 6-10 years. This indicates that most of the members have long duration of membership. Thus, they might have enriched with overall activities of cooperatives service provision and they could have good information of their cooperatives overall performance.

\subsubsection{Service Provision Performance of MPACs}

Well organized and managed cooperative could play a vital role in desirable services provision adequately and promptly to its members. The performance of cooperative could be evaluated among other things by their ability to provide valuable services to members as well as to the community. Cooperative operated primarily to provide benefits to members through marketing, including input distribution and output purchasing, providing training, credit access and distribution of patronage dividend.

\subsubsection{Distribution of Agricultural Inputs}

Inputs such as fertilizer and improved seeds are supposed 
to be the most significant production boosting factors to achieve food self-sufficiency and thereby enhance the income of farming households. In view of this, many efforts are being made to enhance supply and use of fertilizer and other agricultural inputs. Input supply service is one of the important areas of socio-economic activity where MPACs are taking part. Since almost all of the respondents are rural farming households sample cooperatives are providing service of distribution of agricultural inputs such as fertilizer and improved seed. As indicated in figure 3 Chihra Manterno multipurpose agricultural cooperative has made distribution of higher volume of fertilizer specifically, Urea (1523 quintal) and DAP (722.5 quintal) followed by Tach Teda multipurpose agricultural cooperative (1470.5 quintal Urea) and (648 quintal) NPS fertilizer distribution service carried out in collaboration with ACSI.

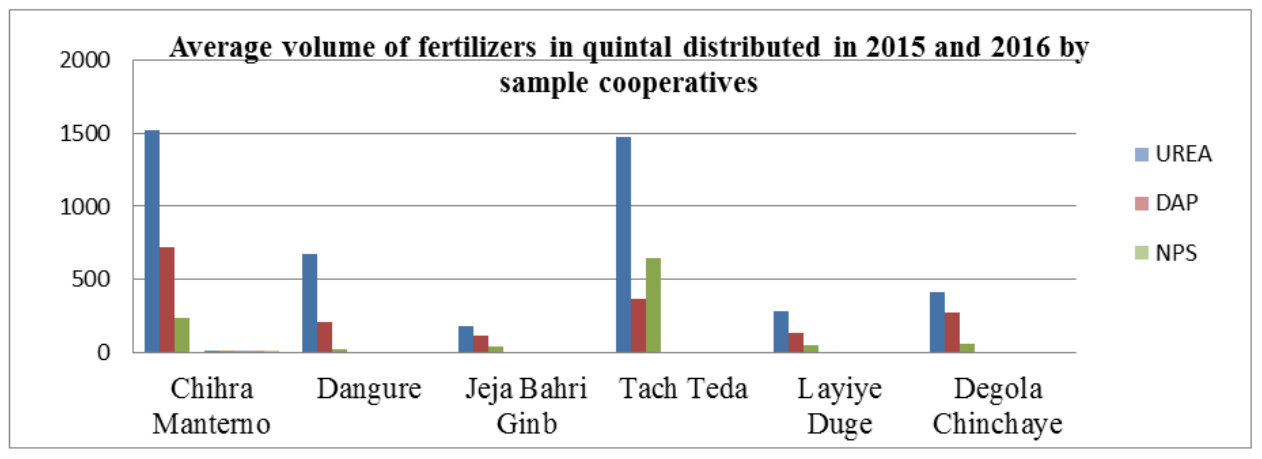

Source: Gondar Zuria district Agricultural input distribution office.

Figure 1. Volume of fertilizers in quintal distributed by sample cooperatives in 2015 and 2016.

\subsubsection{Price Setup in Cooperatives Perceived by Members}

The concern emanate from the very beginning of cooperatives that they are established is to stabilize market prices by enhancing members' bargaining power. In this regard as shown in table 5 of the total respondents $37.8 \%$ have perceived as the output price set in cooperative is high or attractive to sell their farm products through their cooperative where as $39.3 \%$ of the respondents perceived as there is no difference to the other market price. The remaining $18 \%$ and $4.9 \%$ (Table 5) indicates member's perception of medium price (attractive for some products) and low price respectively. This depicts that cooperatives have made to some extent special price arrangement for purchasing member's farm product as incentive to attract members in selling of their farm products through cooperatives as stated [8] farmers want to become member in the cooperative if the cooperative offers higher price for their products than other individual market outlet options.

\subsubsection{Credit access for Member from Cooperatives}

Credit access has primary function in increasing the income of people. Hence, individuals might join to cooperatives by considering access of reliable and cheaper credit compared to other formal lending institutions. Regarding this concern sample respondents were asked and respond as there is low level of access to credit from their cooperatives accounts for $35.2 \%$ of respondents and no access for $34.4 \%$ (Table 5). This reveals that there is low level of credit access to members when they are in difficult to purchase agricultural inputs from their cooperative due to shortage of cash in their hand. However, as portrayed by FGD participants' branches of Amhara credit and saving institute (ACSI) extended to every kebeles' and work at each multipurpose agricultural cooperative site in collaboration to provide credit and saving service to the community. Hence, members can get loan with considerable interest rate to purchase agricultural inputs and other consumer goods from their cooperative.

\subsubsection{Level of Communication or Access to Information}

Efficient communications in cooperative persuade members' involvement and ensure that the members are informed about what is going on in their cooperative. In this regard as indicated in table 5 of the total respondents $41.8 \%$ of members have perceived as there is good level of communication and dissemination of information through meeting and by committee members in each nearby residence. However, $58.2 \%$ of respondents (Table 5) opined as there is poor level of communication in cooperatives related to market and their cooperatives overall activities. This indicates that the management of cooperatives were not informing members to what extent the process of the cooperative is going on and market information that enable members to access lucrative market for their products. This might lead members to hesitate and halt from their active engagement in the cooperatives as stated [2] shortage of timely and valuable marketing information from their cooperatives causes a problem to members to selling their product. It is plausible to assume that for the members information about the market should gain in importance.

Table 5. Member's perception to services rendered by cooperatives.

\begin{tabular}{llll}
\hline Services rendered & Categories & Frequency & Percent \\
\hline \multirow{3}{*}{ Level of } & Very good & 12 & 9.8 \\
communication & Good & 39 & 32 \\
& Poor & 36 & 29.5 \\
& Very poor & 35 & 28.7 \\
\multirow{2}{*}{ Price setup in } & High price & 46 & 37.8 \\
cooperatives & Medium price & 22 & 18 \\
& Low price & 6 & 4.9 \\
& No difference & 48 & 39.3 \\
\hline
\end{tabular}




\begin{tabular}{llll}
\hline Services rendered & Categories & Frequency & Percent \\
\hline \multirow{4}{*}{ Credit access } & Highly accessible & 8 & 6.6 \\
& Moderately accessible & 29 & 23.8 \\
& Low accessible & 43 & 35.2 \\
& No access & 42 & 34.4 \\
& Total & 122 & 100 \\
\hline
\end{tabular}

Source: Survey data, 2017.

\subsubsection{Access to Training}

Education and training is one of the seven ICA principles of cooperatives and the development of cooperatives highly depends on the members understanding about the activities of their cooperative and its role. In line with this, the respondents were asked whether they have been given cooperative oriented education and training by their cooperatives. As indicated in figure 4 about $45.1 \%$ of the respondent members have got cooperative oriented training and education. Whereas, $54.9 \%$ of the cooperative members have asserted as they have not got access to participate in cooperative oriented training and education this might have negative impact on the active involvement of members in the cooperative. Hence, it could have negative impact on cooperatives performance and their members' satisfaction.

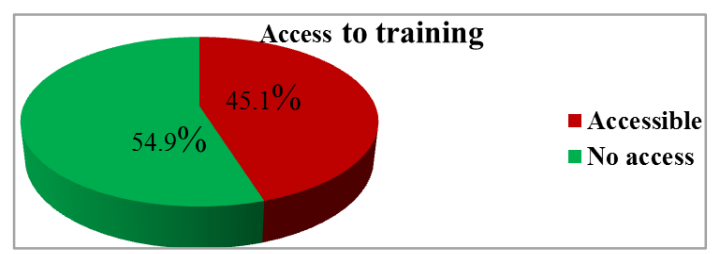

Figure 4. Access to training for members from their cooperative.

\subsubsection{Dividend Earning or Patronage Refund}

As per the cooperative proclamation of Ethiopia 147/1998 article 33 from the profit $30 \%$ should be reallocated as reserve fund for cooperative and remaining $70 \%$ should distributed to member's as dividend as per the wishes of the General Assembly. Hence, distribution of the dividend is one of the promotional strategies which encourage members to increase their involvement in cooperative activities. In this regard respondents were asked whether they have got dividend at least once or not and their response indicated in the figure below.

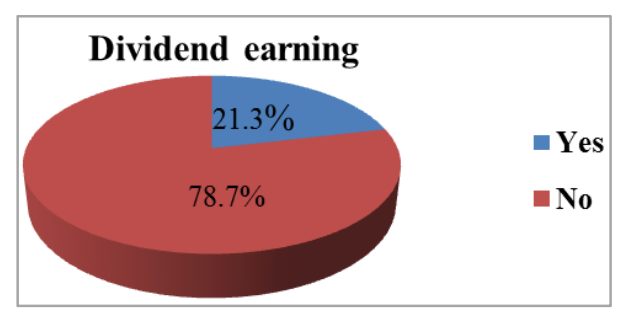

Figure 5. Distribution of members by dividend earning.

As shown in figure 5 of the total respondents $78.7 \%$ of the members have not gained dividend from their cooperatives whereas $21.3 \%$ of respondents have got dividend distributed according to by law of the cooperatives. Chihra Manterno MPAC distribute dividend to members every year but the other cooperatives are not conducting dividend distribution practice to members depend on their participation in marketing and share capital they contributed. This gap probably might reduce member's level of involvement in activity related to cooperatives. Based on key informants opinion this is because of the cooperative management's intention to increase their internal financial capital by owner's equity to expand the cooperative business operation rather than looking for external financial sources and to increase the sense of ownership of members to the cooperative in the long run. Considering the desire for independence and autonomy of cooperative borrowing from within the membership is preferable.

\subsection{Determinants to Performance of MPACs}

Hypothesized explanatory variables were checked for the existence of multicollinearity through variance inflation factor (VIF) less than cutoff 10 for association between the continuous variables and contingency coefficients (CC) less than 0.75 for discrete variables. According to the results, no significant problem of multicollinearity was observed among explanatory variables. Therefore, all 13 hypothesized (six continuous) and (seven discrete) explanatory variables were included in the model. With reference to degree of member's satisfaction to overall performance of MPACs as indicator (dependent variable), the result of the model analysis showed that four variables were found to be significant at $5 \%$ and two at $10 \%$ (Table 6 ) level of significance. The signs for these factors showed the direction of the relationship with members' satisfaction and the coefficient weight revealed variable importance (magnitude) towards affecting members' satisfaction to overall performance of their cooperatives. However, one cannot notify by how much the change in these explanatory variables affect the response variable [9]. To determine this kind of situation undertaking an estimate of the marginal effects of these changes is valuable solution. It shows by how much the probability of a change in the dependent or response variable is expected to increase or decrease for a unit change in explanatory variables.

Family size is statistically significant at $10 \%$ level of significance and influencing the satisfaction of the members to overall performance of their cooperatives negatively. The possible rationale for this could be as numbers of family increase in households there would be need for more volume of consumer good for consumption and high expenditure to meet their needs. Thus, members become dissatisfied if they do not have access to more amount of commodities (consumer goods) through their cooperatives with reasonable prices. As family member increase individual member's satisfaction to service rendered by their cooperatives decrease by $5.49 \%$. This result is in conformity with the finding study conducted on performance of coffee marketing cooperatives and member's satisfaction [10]. 
Table 6. Maximum likelihood estimate of probit model for member's satisfaction to overall performance of their cooperatives.

\begin{tabular}{|c|c|c|c|c|}
\hline Explanatory variables & Estimated coefficient & Standard error & $\mathbf{P}>|\mathbf{z}|$ & Coefficient for marginal effect \\
\hline Age & -.0015644 & .0134759 & 0.908 & -.0006229 \\
\hline Family size & -.1378629 & .0802745 & $0.086^{*}$ & -.0548942 \\
\hline Educational status & -.3859689 & .3067239 & 0.208 & -.1524555 \\
\hline Duration of membership & .0100435 & .0456247 & 0.826 & .0039991 \\
\hline Numbers of shareholding & .4599336 & .2353161 & $0.051 *$ & .183136 \\
\hline Distance to cooperatives & .0031931 & .0072087 & 0.658 & .0012714 \\
\hline Working relationship & .5581834 & .2606712 & $0.032 * *$ & .2195774 \\
\hline Level of communication & .3498204 & .2194353 & 0.111 & .1392912 \\
\hline Membership to union & 27.18287 & 12.90413 & $0.035 * *$ & 9999997 \\
\hline Degree of government support & .1126436 & .1926971 & 0.559 & .0448524 \\
\hline Cooperative age & -.9546454 & .4621384 & $0.039 * *$ & -.38012 \\
\hline Degree of corruption & -.3673221 & .1449621 & $0.011 * *$ & -.14626 \\
\hline Constant & 10.25542 & 5.192538 & 0.048 & - \\
\hline LR chi2 (13) & 35.54 & & & \\
\hline Log likelihood & -66.7275 & & & \\
\hline
\end{tabular}

** and * represents $5 \%$ and $10 \%$ level of significance respectively.

Numbers of shareholding influence the satisfaction of members to overall performance of MPACs positively and significant at $10 \%$ probability level of significance as it was expected. This implies that as the number of shareholding of farmer members increases their involvement in cooperatives affairs and service utilization increase and thereby become satisfied when cooperatives are in a position to render desired services for their members i.e cooperatives are performing well. An increment in numbers of shareholding by one results an increase to satisfaction of members to services provision performance of their cooperatives by $18.31 \%$.

The result of the model depicted that smooth working relationship between members and employees of cooperativeshad positive significant relationship with degree of member's satisfaction to overall performance of their cooperatives at $5 \%$ level of significance which is similar with the prior expectation. This relation shows that when there is smooth relationship in cooperative working environment between the members and cooperative managements members become satisfied by $21.95 \%$. In collective action activities, the existence of mutual trust between members and the cooperative management will have an impact in the successful operation of cooperatives and its member's satisfaction. It is expected that members that trust cooperative managements and perceive that the decisions of their cooperative allow them to access their needs intern this stimulate members to feel confident and satisfied with the cooperative. This finding is in line with finding [11].

The result of the model showed that membership to union influence member's satisfaction to overall performance of their cooperatives positively as hypothesized earlier and it is found statistically significant at $5 \%$ significance level. As the primary cooperatives become member to cooperative union member's satisfaction to overall performance of their cooperative increase by almost $100 \%$. This is because of the advantages obtained from cooperative union through marketing of member's produce in the local and international market, providing market information, supplying agricultural inputs with transportation aid, and training and credit services for the member primary cooperatives.

Cooperative age influence degree of member's satisfaction to overall performance of their cooperative negatively at $5 \%$ level of significance. When the age of cooperative increase by one year degree of member's satisfaction to overall performance of their cooperative decrease by $38 \%$. The probable reason for this could be older cooperatives are expected to have facilities and equipment that are more fully depreciated or worn out resulting in a lower asset base. Moreover, poor management of cooperative experienced from past history of Ethiopian cooperative movement could have impact on the performance of aged cooperative as well as satisfaction of their members. This result is on the contrary to the result of the study done on member's satisfaction of dairy marketing cooperative [12].

Degree of corruption has negative relationship with member's satisfaction to overall performance of their cooperatives and it is statistically significant at $5 \%$ level of significance. The possible reason for this effect could be member's felt as there is persistently high level of malpractices/misappropriation of cooperative properties; giving priority for benefit of relatives during service delivery so that the members would not be satisfied. This is found similar to the finding [13]. Cooperatives would have low level of performance and dissatisfied members if there is persistent misappropriation in the cooperative management practice.

\section{Conclusion and Recommendation}

MPACs in the study area are involved in distribution of agricultural inputs; such as, fertilizer and improved seeds and basic consumer goods like, sugar and edible oil to farmers. However, little effort were made in marketing (purchasing) farmers produces that enable farmers to access market with reasonable price from their cooperatives nearby their residence 
in order to reduce cost of transaction, labour, time and unfair exploitation by private traders. Low level of market performance of multipurpose cooperatives could be attributed to inadequate management and entrepreneurial skills among staff and elected committee members, limited promotion and communication skills, and financial constraints that make it impossible to recruit and retain a good caliber of staff and to provide capacity building among members and leaders. The probit regression analysis results revealed that out of thirteen (six continuous) and (seven discrete explanatory) variables those were included in the model, family size, numbers of shareholding, membership to union, working relationship, cooperative age and degree of corruption were found to be determinants to degree of members' satisfaction to overall performance of MPACs. Among these significant variables numbers of shareholding, membership to union and working relationship were found to be significantly and positively related to members' satisfaction to overall performance of MPACs. On the other hand, family size, cooperative age and degree of corruption were found to be significantly influence degree of member's satisfaction to their cooperative overall performance negatively. Based on the aforementioned conclusive remarks the following recommendations are forwarded which might help for further intervention to enhance performance of cooperatives.

1) The positive effect of being a member of cooperative union by primary cooperatives on degree of member's satisfaction indicates that membership to union is a very important determinant of members' satisfaction to overall performance of their cooperatives. Therefore, cooperative management and staff members should strive to render valuable services to its members through grasping the opportunities obtained from being members of cooperative union.

2) The significant effect of working relationship to member's satisfaction as indicator of their cooperative performance indicates that this variable is a very important determinant of member's satisfaction to performance of their cooperatives. Therefore, cooperative management and staff members should strive to render different valuable services to its members through creating a smooth working environment in their cooperative in order to satisfy households in such a way that reduce the leave up of households from cooperatives.

3) The potential of cooperatives in output marketing in the study area is found to be very limited this might be due to lack of working capital, trained manpower, integrated effective management. Thus, the cooperative managements should strive to minimize their gaps and coordinate their effort to carry out output marketing so as to serve their members for market access in time saving and cost effective manner and to get profit for the growth of cooperative internal capital.

\section{References}

[1] Bezabih Emana, (2009). Cooperatives: A Path to Economic and Social Empowerment in Ethiopia, CoopAfrica, Working Paper No. 9, ILO, Rome.

[2] Veerakumaran, G., (2007). Ethiopian Cooperative MovementAn Explorative Study.

[3] Bernard, T., Gashaw, Tesfaye,\& Solomon, Lema., (2013). Agricultural cooperatives in Ethiopia: Results of the 2012 ATA Baseline Survey International Food Policy Research Institute Washington, DC.

[4] Destahun Haile, (2007). Cooperative approach to local development: the case of coffee cooperative unions in coffee growing regions of Ethiopia, M. A. thesis, Addis Ababa University, Ethiopia.

[5] Rao. P. M. S and Tesfay Gebrehiwet, (2014). Member control practices in cooperatives. Journal of Business Management and Social Sciences Research (JBM and SSR); ISSN No: 2319-5614, Volume 3, No. 5.

[6] Getnet, Kindie. \& Anullo, Tesfaye., (2012). Agricultural cooperatives and rural livelihoods: Evidence from Ethiopia. Annals of Public and Cooperative Economics, 83 (2), Pp. 181198.

[7] CSA (Central Statistical Authority), (2007). Summary and statistical report of the 2007 population and housing census.

[8] Mensah, O., Damoah, O. \& Robert, A., (2012). Assessing Farmer's Satisfaction of Agronomic Services Received in Ghana Using the SERVQUAL Model- a Case Study of Kumasi Metropolis. International journal of Business and Social Science, 3 (19), Pp. 51-60.

[9] Greene, W. H., (2002). Econometric Analysis. Fivth Edition, Pretice Hall International, Inc. New York.

[10] Demeke Tilahun, (2007). Performance of Coffee Marketing Cooperatives and Members Satisfaction in Dale District: SNNPRSSouthern. M. Sc. Thesis, Haramaya University, Ethiopia.

[11] Costa, A. C. 2003. Work team trust and effectiveness. Personnel Review, 32, 605-623.

[12] Almaz, Mesfine., (2008). Comparative Study on the Performance of Dairy Cooperative Input and output Marketing in Astbie Womerta, Alamata and Enderta woreda in Tigray Region. M.Sc Thesis, Mekelle University, Ethiopia.

[13] Dejene Debebe. \& Matthews Haile., (2016). A Study on factors affecting farmer's cooperative membership increment in Bench Maji Zone, Southwestern Ethiopia., 6 (2), Pp. 129-138. 